\title{
A New Model for Selecting Third-Party Reverse Logistics Providers in the Presence of Multiple Dual-Role Factors
}

\author{
Reza Farzipoor Saen \\ Department of Industrial Management, Faculty of Management and Accounting, Islamic Azad \\ University-Karaj Branch, Karaj, Iran, P. O. Box: 31485-313
}

Tel: 0098 (261) 4418144-6

Fax: 0098 (261) 4418156

E-mail: farzipour@yahoo.com

\begin{abstract}
In traditional models of data envelopment analysis (DEA) it is assumed that decision making units (DMUs) do not have dual-role factors. This paper proposes a model for selecting third-party reverse logistics (3PL) provider in the presence of multiple dual-role factors. A numerical example demonstrates the application of the proposed method.
\end{abstract}

Keywords: Data envelopment analysis, Third-party reverse logistics provider, 3PL provider, Multiple dual-role factors

\section{Introduction}

Reverse logistics is the physical running from the area of consumer to the area of source. The enterprises make more benefits during the process of recycle and reuse. In particular, the manufacturer collects the used products from customers and then sells to customers as new ones after remanufacturing. Reverse logistics mainly focuses on how to take back the returns and recover them efficiently and economically. It is favorable to save natural resource, protect environment, enhance enterprises competition and increase economic benefits for enterprises to implement reverse logistics.

At present, the lucubration or the mathematic model of the management in reserve logistics area is little. The reserve logistics is managed and evaluated mainly by the cost. It is undeniable that the cost is an important index to evaluate the status of reverse logistics, but it is not comprehensive because of the complexity in reverse logistics. So it is necessary to build an evaluation model from different point of view, (Zhang and Lu, 2006). 
Data envelopment analysis (DEA), developed by Charnes et al. (1978), provides a nonparametric methodology for evaluating the efficiency of each of a set of comparable decision making units (DMUs), relative to one another.

In the conventional application of DEA, it is assumed that one can, given a collection of available measures, clearly specify which will constitute inputs and which outputs. For example, in a conventional study of efficiency of bank branch operations, outputs used are the standard counter transactions such as deposits and withdrawals, and inputs are resources such as various staff types. Suppose, however, that one wishes to evaluate each branch's efficiency to attract investments. In this case, a factor such as the number of "high value" customers, could serve as either an input or an output. From one perspective, such a measure may play the role of proxy for future investment, hence can reasonably be classified as an output. On the other hand, it can legitimately be considered as an environmental input that aids the branch in generating its existing investment portfolio (Cook and Zhu, 2007).

Similar arguments can be made regarding the evaluation of research productivity by universities, such as described in Beasley $(1990,1995)$. There, "research income" is treated as both an output and input.

To deal with the dual-role factor, Cook et al. (2006) developed a model that considers just a single factor and does not consider multiple dual-role factors.

The objective of this paper is to propose a model for selecting third-party reverse logistics (3PL) providers in the presence of multiple dual-role factors. This paper depicts the 3PL provider selection process through a DEA model, while allowing for the incorporation of multiple dual-role factors.

This paper proceeds as follows. In Section 2, literature review is presented. Section 3 discusses the proposed method for 3PL provider selection. Numerical example and managerial implications are discussed in Sections 4 and 5, respectively. Section 6 discusses concluding remarks.

\section{Literature review}

Some mathematical programming approaches have been used for 3PL provider selection in the past. To select 3PL vendors, Zhang et al. (2004) applied an analytic hierarchy process (AHP) based model to a case study. Zhang and Feng (2007) used fuzzy AHP to discuss a selection approach of reverse logistics provider through a practical case. Meade and Sarkis (2002) modeled new factors for including in 3PL provider selection problem within a decision making framework. To this end, they applied analytic network process (ANP). To 
assist decision makers in determining the "most appropriate" 3PL providers in the presence of vagueness, Efendigil et al. (2008) developed a two-phase model based on neural networks and fuzzy AHP in a holistic manner.

However, AHP and ANP have two main weaknesses. First subjectivity of AHP and ANP is a weakness. The decision maker provides the values for the pairwise comparisons and, therefore, the model is very dependent on the weightings provided by the decision maker. Second the time necessary for completion of such a model is a weakness. The number of pairwise comparisons required could become cumbersome. Meanwhile, when the number of alternatives and criteria grows, the pairwise comparison process becomes difficult, and the risk of generating inconsistencies grows, hence jeopardizing the practical applicability of AHP and ANP.

Bottani and Rizzi (2006) presented a multi-attribute approach for the selection and ranking of the most suitable 3PL provider. Their approach is based on the TOPSIS (Technique for Order Preference by Similarity to Ideal Solution) technique and the fuzzy set theory. Cao et al. (2007) proposed a two-stage method based on the social welfare function and TOPSIS. In the first stage, they used the social welfare function theory for selecting potential providers from too many 3PL providers. Then, TOPSIS was utilized for final selection, avoiding the subjective estimation of experts. Experiments are conducted to evaluate the quality of the proposed approach by using a case company. Qureshi et al. (2007) presented the methodology to earmark potential 3PL services providers using TOPSIS with interval data. Criteria importance weights have been derived using AHP in order to judge 3PL services providers. As well, they illustrated the extended TOPSIS methodology, by a case problem.

Haas et al. (2003) applied DEA to help logistics managers for evaluating reverse logistics channels. Their approach provides logistics managers with an understanding of the cost interactions and efficiencies of the channel members in reverse logistics channels. In an effort to help 3PL providers enhance productivity and price leverage in the increasingly competitive 3PL market, Min and Joo (2006) developed a meaningful set of financial benchmarks that dictate best practices. They proposed a DEA that is proven to be useful for measuring the operational efficiency of various profit or non-profit organizations. Recently, Farzipoor Saen (2009) proposed a method for selecting the best 3PL providers in the presence of both cardinal and ordinal data.

However, all of the abovementioned references do not consider dual-role factors. A technique that can deal with dual-role factors is needed to better model such situation. 
To the best of author's knowledge, there is not any reference that discusses 3PL provider selection in the presence of multiple dual-role factors. The approach presented in this paper has some distinctive features.

- The proposed model does not demand exact weights from the decision maker.

- The proposed model considers multiple dual-role factors for 3PL provider selection.

- For the first time, the proposed model is used for the problem of 3PL provider selection.

- The proposed model can be easily computerized, enabling it to serve as a decision making tool to assist decision makers.

\section{Proposed method for 3PL provider selection}

Consider a situation where members $k$ of a set of $K$ DMUs are to be evaluated in terms of $R$ outputs $Y_{k}=\left(y_{r k}\right)_{r=1}^{R}$ and $I$ inputs $X_{k}=\left(x_{i k}\right)_{i=1}^{I}$. In addition, assume that a particular factor is held by each DMU in the amount $w_{k}$, and serves as both an input and output factor. The proposed model for considering single dual-role factor is as follows (Cook et al., 2006).

$$
\max \frac{\left(\sum_{r=1}^{R} \mu_{r} y_{r o}+\gamma w_{o}-\beta w_{o}\right)}{\sum_{i=1}^{I} v_{i} x_{i o}},
$$

st

$$
\begin{aligned}
& \sum_{r=1}^{R} \mu_{r} y_{r k}+\gamma w_{k}-\beta w_{k}-\sum_{i=1}^{I} v_{i} x_{i k} \leq 0, \quad k=1, \ldots, K \\
& \mu_{r}, v_{i}, \gamma, \beta \geq 0 .
\end{aligned}
$$

The linear programming form of model (1) is as follows: 


$$
z_{o}^{*}=\max \sum_{r=1}^{R} \mu_{r} y_{r o}+\gamma w_{o}-\beta w_{o},
$$

st

$$
\begin{aligned}
& \sum_{i=1}^{I} v_{i} x_{i o}=1, \\
& \sum_{r=1}^{R} \mu_{r} y_{r k}+\gamma w_{k}-\beta w_{k}-\sum_{i=1}^{I} v_{i} x_{i k} \leq 0, \quad k=1, \ldots, K \\
& \mu_{r}, v_{i}, \gamma, \beta \geq 0 .
\end{aligned}
$$

where $\mu_{r}$ is the weight given to output $r$ and $v_{i}$ is the weight given to input $i . \mathrm{DMU}_{o}$ is the DMU under consideration. DMU $\mathrm{DM}_{o}$ consumes $x_{i o}(i=1, \ldots, I)$, the amount of input $i$, to produce $y_{r o}(r=1, \ldots, R)$, the amount of output $r$.

Now, to demonstrate how to consider multiple dual-role factors in the model, the new model is presented. Assume that some factors are held by each DMU in the amount $w_{f k}$ $(f=1, \ldots, F)$, and serve as both an input and output factors. The proposed model for considering multiple dual-role factors is as follows:

$$
\max \frac{\left(\sum_{r=1}^{R} \mu_{r} y_{r o}+\sum_{f=1}^{F} \gamma_{f} w_{f o}-\sum_{f=1}^{F} \beta_{f} w_{f o}\right)}{\sum_{i=1}^{I} v_{i} x_{i o}},
$$

st

$$
\begin{aligned}
& \sum_{r=1}^{R} \mu_{r} y_{r k}+\sum_{f=1}^{F} \gamma_{f} w_{f k}-\sum_{f=1}^{F} \beta_{f} w_{f k}-\sum_{i=1}^{I} v_{i} x_{i k} \leq 0, \quad k=1, \ldots, K \\
& \mu_{r}, v_{i}, \gamma_{f}, \beta_{f} \geq 0 .
\end{aligned}
$$

The linear programming form of model (3) is as follows:

$$
e_{o}^{*}=\max \sum_{r=1}^{R} \mu_{r} y_{r o}+\sum_{f=1}^{F} \gamma_{f} w_{f o}-\sum_{f=1}^{F} \beta_{f} w_{f o},
$$

st

$$
\begin{aligned}
& \sum_{i=1}^{I} v_{i} x_{i o}=1, \\
& \sum_{r=1}^{R} \mu_{r} y_{r k}+\sum_{f=1}^{F} \gamma_{f} w_{f k}-\sum_{f=1}^{F} \beta_{f} w_{f k}-\sum_{i=1}^{I} v_{i} x_{i k} \leq 0, \quad k=1, \ldots, K \\
& \mu_{r}, v_{i}, \gamma_{f}, \beta_{f} \geq 0 .
\end{aligned}
$$


One of three possibilities exists in regard to the sign of $\hat{\gamma}_{f}-\hat{\beta}_{f}$, where $\hat{\gamma}_{f}, \hat{\beta}_{f}$ are the optimal values from model (4); $\hat{\gamma}_{f}-\hat{\beta}_{f}>0,=0$, or $<0$. It is useful to comment here on an interesting relationship that exists between the constant returns to scale (CRS) model (model (4)) and the standard (no dual-role factors present) variable returns to scale (VRS) model of Banker et al. (1984). Specifically, the VRS model with outputs $Y$ and inputs $X$ is given by:

$$
\max \left(\sum_{r=1}^{R} \mu_{r} y_{r o}-\mu_{o}\right) / \sum_{i=1}^{I} v_{i} x_{i o},
$$

st

$$
\begin{array}{ll}
\sum_{r=1}^{R} \mu_{r} y_{r k}-\mu_{o}-\sum_{i=1}^{I} v_{i} x_{i k} \leq 0 & k=1, \ldots K, \\
\mu_{r}, v_{i} \geq 0, \quad \mu_{o} \text { unrestricted in sign. }
\end{array}
$$

In the CRS model, $\mu_{o}$ is set to zero, and the supporting hyperplane to any facet of the frontier passes through the origin. Otherwise, $\mu_{o}$ is a form of "Y-intercept" to use an analogy with regression techniques. It is well known that the sign of $\mu_{o}$ identifies the "returns to scale" status of the $\mathrm{DMU}_{o}$. It is useful therefore to examine the three cases in regard to this sign, which will allow us to make important interpretations pertaining to the sign of the variables $\hat{\gamma}_{f}-\hat{\beta}_{f}$.

Case 1: If $\mu_{o}>0$ in model (5), then the $\mathrm{DMU}_{o}$ is said to be experiencing decreasing returns to scale, Banker et al. (1984). Thus, the marginal return, in terms of output, is less than the amounts of input required to produce that output. In "returns to scale" terminology, this DMU is not operating at the most productive scale size (MPSS), and would benefit from a reduction in size. A somewhat similar interpretation can be made in model (4) when $\hat{\gamma}_{f}-\hat{\beta}_{f}<0$. Using research funding as the illustrative example, one might argue that $\mathrm{DMU}_{o}$ would experience an improvement in efficiency with fewer research dollars. That is, in this particular university, these factors are at a level where diminishing returns have set in, hence less of these factors would improve its performance ratio. One can say that in this case, the dual-role factors are "behaving like inputs".

Case 2: If $\mu_{o}<0$, then $\mathrm{DMU}_{o}$ is experiencing increasing returns to scale, and again it is not at the MPSS. This case is analogous to $\hat{\gamma}_{f}-\hat{\beta}_{f}>0$ in model (4), meaning that this university's efficiency would benefit from increased research dollars. Specifically, these 
factors are at a level where they are "behaving like outputs", hence more of these factors are better, and would lead to an increase in efficiency.

Case 3: If $\mu_{o}=0$, then $\mathrm{DMU}_{o}$ is experiencing constant returns to scale, and the VRS model (5) reduces to the standard CRS model of Charnes et al. (1978). The $\mathrm{DMU}_{o}$ would then be operating at the MPSS. In a university setting, the analogous situation would be to have $\hat{\gamma}_{f}-\hat{\beta}_{f}=0$, meaning that the funding is at an equilibrium or optimal level.

In the next section, a numerical example is presented.

\section{Numerical example}

The data set for this example is partially taken from Talluri and Baker (2002) and contains specifications on eighteen 3PL providers. The 3PL provider input considered is total cost of shipments (TC) ${ }^{1}$. The output utilized in the study is revenue from the sale of recyclables (R). The dual-role factors are ratings for service-quality experience (EXP) and service-quality credence (CRE).

EXP and CRE could serve as either inputs or outputs. From the perspective of decision maker who intends to select the best 3PL providers, such measures may play the role of proxy for "high quality of services", hence can reasonably be classified as outputs. On the other hand, from the perspective of 3PL provider that intends to supply reverse logistics services, they can be considered as inputs that help the 3PL provider in obtaining more customers. The reason why EXP and CRE are considered as inputs is that they are as a means to attract more customers for 3PL providers. For more information on the data set, please refer to Talluri and Baker (2002). Table 1 depicts the 3PL provider's attributes.

Applying Model (4), the efficiency scores of 3PL providers (DMUs) and their inputs/outputs behavior have been presented in Table 2.

\footnotetext{
${ }^{1}$ The inputs and outputs selected in this paper are not exhaustive by any means, but are some general measures that can be utilized to evaluate 3PL providers. In an actual application of this methodology, decision makers must carefully identify appropriate inputs and outputs measures to be used in the decision making process.
} 
Table 1. Related attributes for eighteen 3PL providers

\begin{tabular}{|c|c|c|c|c|}
\hline $\begin{array}{c}3 \text { 3P provider } \\
\text { No. } \\
(\mathrm{DMU})\end{array}$ & Input & \multicolumn{2}{|c|}{ Dual-role factors } & Output \\
\cline { 2 - 5 } & $x_{1 k}$ & $\begin{array}{c}\text { EXP } \\
w_{1 k}\end{array}$ & $\begin{array}{c}\text { CRE } \\
w_{2 k}\end{array}$ & $\begin{array}{c}\text { R (1000 \$) } \\
y_{1 k}\end{array}$ \\
\hline 1 & 253 & 240 & 90 & 187 \\
\hline 2 & 268 & 210 & 80 & 194 \\
\hline 3 & 259 & 270 & 70 & 220 \\
\hline 4 & 180 & 200 & 70 & 160 \\
\hline 5 & 257 & 160 & 70 & 204 \\
\hline 6 & 248 & 230 & 80 & 192 \\
\hline 7 & 272 & 200 & 90 & 194 \\
\hline 8 & 330 & 170 & 60 & 195 \\
\hline 9 & 327 & 180 & 70 & 200 \\
\hline 10 & 330 & 170 & 60 & 171 \\
\hline 11 & 321 & 200 & 80 & 174 \\
\hline 12 & 329 & 210 & 100 & 209 \\
\hline 13 & 281 & 300 & 90 & 165 \\
\hline 14 & 309 & 250 & 80 & 199 \\
\hline 15 & 291 & 250 & 90 & 188 \\
\hline 16 & 334 & 240 & 80 & 168 \\
\hline 17 & 249 & 210 & 70 & 177 \\
\hline 18 & 216 & 200 & 80 & 167 \\
\hline & & & & \\
\hline
\end{tabular}

Model (4) identified 3PL providers 3, 4, 5, 7, 8, 12, and 18 to be efficient with a relative efficiency score of 1 . The remaining 3PL providers with relative efficiency scores of less than 1 are considered to be inefficient. Therefore, decision maker can choose one or more of these efficient 3PL providers.

The 3PL providers $1,2,5,6,7,8,9,10,11,12,15,17$, and 18 are those that EXP is behaving like an input. Therefore, these DMUs are said to be experiencing decreasing returns to scale.

The 3PL providers 3, 13, 14, and 16 are those that EXP is behaving like an output, where more of such factor would improve the efficiencies of related 3PL providers. Therefore, these DMUs are said to be experiencing increasing returns to scale.

The 3PL provider 4 is the DMU that EXP is in equilibrium. Therefore, this DMU is said to be experiencing constant returns to scale. 
Table 2. Efficiency scores and input/output behavior

\begin{tabular}{|c|c|c|c|c|c|c|c|}
\hline $\begin{array}{c}\text { 3PL provider } \\
\text { No. } \\
\text { (DMU) }\end{array}$ & Efficiency & $\hat{\gamma}_{1}$ & $\hat{\beta}_{1}$ & $\hat{\gamma}_{1}-\hat{\beta}_{1}$ & $\hat{\gamma}_{2}$ & $\hat{\beta}_{2}$ & $\hat{\gamma}_{2}-\hat{\beta}_{2}$ \\
\hline 1 & 0.939 & 0 & 0.014 & -0.014 & 0.014 & 0 & 0.014 \\
\hline 2 & 0.868 & 0 & 0.003 & -0.003 & 0.011 & 0 & 0.011 \\
\hline 3 & 1 & 0.004 & 0 & 0.004 & 0 & 0.003 & -0.003 \\
\hline 4 & 1 & 0 & 0 & 0 & 0.014 & 0 & 0.014 \\
\hline 5 & 1 & 0 & 0.001 & -0.001 & 0 & 0 & 0 \\
\hline 6 & 0.886 & 0 & 0.0008 & -0.0008 & 0 & 0.002 & -0.002 \\
\hline 7 & 1 & 0 & 0.004 & -0.004 & 0.02 & 0 & 0.02 \\
\hline 8 & 1 & 0 & 0.003 & -0.003 & 0 & 0.04 & -0.04 \\
\hline 9 & 0.754 & 0 & 0.0006 & -0.0006 & 0 & 0.001 & -0.001 \\
\hline 10 & 0.629 & 0 & 0.0006 & -0.0006 & 0 & 0.001 & -0.001 \\
\hline 11 & 0.694 & 0 & 0.003 & -0.003 & 0.009 & 0 & 0.009 \\
\hline 12 & 1 & 0 & 0.007 & -0.007 & 0.02 & 0 & 0.02 \\
\hline 13 & 0.996 & 0.004 & 0 & 0.004 & 0 & 0.002 & -0.002 \\
\hline 14 & 0.744 & 0.004 & 0 & 0.004 & 0 & 0.002 & -0.002 \\
\hline 15 & 0.804 & 0 & 0.001 & -0.001 & 0.01 & 0 & 0.01 \\
\hline 16 & 0.655 & 0.003 & 0 & 0.003 & 0 & 0.002 & -0.002 \\
\hline 17 & 0.821 & 0 & 0.0008 & -0.0008 & 0 & 0.002 & -0.002 \\
\hline 18 & 1 & 0 & 0.002 & -0.002 & 0.02 & 0 & 0.02 \\
\hline
\end{tabular}

As well, the 3PL providers 3, 6, 8, 9, 10, 13, 14, 16, and 17 are those that CRE is behaving like an input. Therefore, these DMUs are said to be experiencing decreasing returns to scale.

The 3PL providers $1,2,4,7,11,12,15$, and 18 are those that CRE is behaving like an output, where more of such factor would improve the efficiencies of related 3PL providers. Therefore, these DMUs are said to be experiencing increasing returns to scale.

The 3PL provider 5 is the DMU that CRE is in equilibrium. Therefore, this DMU is said to be experiencing constant returns to scale.

\section{Managerial implications}

The past decade has witnessed ever-increasing concern regarding the disposal of consumer goods, since many of these products contain both large volumes of waste and substantial quantities of toxic heavy metals. Manufacturers have encountered escalating pressure from both governments and environmentally focused groups to 'reduce', 'recycle' and 'reuse' their industrial waste.

At present, reverse logistics has been regarded as a focus problem. The effective management of reverse logistics is helpful to environmental protection, and it can bring the obvious economic benefits to enterprises. Many companies do not possess enough resource 
or competence to manage their reverse logistics activities, thus they have to choose the third party reverse logistics provider to those activities.

In this paper, the proposed model determines whether in a DMU the factors are behaving predominantly like inputs, hence the DMU would benefit from having less of the factors, like outputs where more of the factors are desirable, or where they are in equilibrium. Meanwhile, these ideas were connected to those involving increasing, decreasing and constant returns to scale.

To make DEA effective, managers must establish key criteria of 3PL provider selection problem. There is no restriction on the types of data which can be collected, with one exception, that it should not be in ratio form.

The important element in the use of DEA is that it opens possibilities for new directions in examining operations within 3PL provider systems where multiple outputs and inputs must be considered without explicit knowledge of the underlying relationships. This paper illustrates this with respect to 3PL provider selection problem. A difficult part of the task is undoubtedly finding appropriate criteria.

\section{Concluding remarks}

In the current paper, the modification to the traditional models of DEA that permits the inclusion of multiple dual-role factors in the analysis was developed. The proposed model was applied for selecting 3PL providers. The problem considered in this study is at initial stage of investigation and much further researches can be done based on the results of this paper. Some of them are as follows:

Similar research can be repeated for dealing with ordinal data and bounded data in the conditions that dual-role factors exist. Other potential extension to the methodology includes the case that some of the 3PL providers are slightly non-homogeneous. One of the assumptions of all the classical models of DEA is based on complete homogeneity of DMUs (3PL providers), whereas this assumption in many real applications cannot be generalized. In other words, some inputs and/or outputs are not common for all the DMUs occasionally. Therefore, there is a need to a model that deals with these conditions.

In this study, the proposed model has been applied to a problem related to 3PL provider selection. However, the same models could be applied, with minor modifications, to other problems related to selection of technologies, international markets, personnel and many other problems. 


\section{Acknowledgements}

The author wishes to thank two anonymous reviewers for their valuable suggestions and comments.

\section{References}

Banker R. D., Charnes A., Cooper W. W., Some Methods for Estimating Technical and Scale Inefficiencies in Data Envelopment Analysis, Management Science, Vol. 30, No. 9 (1984) pp. 1078-1092.

Beasley J., Comparing University Departments, Omega, Vol. 8, No. 2 (1990) pp. 171-183.

Beasley J., Determining Teaching and Research Efficiencies, Journal of the Operational Research Society, Vol. 46, No. 4 (1995) pp. 441-452.

Bottani E., Rizzi A., A Fuzzy TOPSIS Methodology to Support Outsourcing of Logistics Services, Supply Chain Management: An International Journal, Vol. 11, No. 4 (2006) pp. 294-308.

Cao J., Wang W. W., Cao G., Integration of the Social Welfare Function and TOPSIS Algorithm for 3PL Selection, Proceedings of the Fourth International Conference on Fuzzy Systems and Knowledge Discovery, Vo. 3 (2007) pp. 596-600.

Charnes A., Cooper W. W., Rhodes E., Measuring the Efficiency of Decision Making Units, European Journal of Operational Research, Vol. 2, No. 6 (1978) pp. 429-444.

Cook W. D., Green R. H., Zhu J., Dual-Role Factors in Data Envelopment Analysis, IIE Transactions, Vol. 38, No. 2 (2006) pp. 105-115.

Cook W. D., Zhu J., Classifying Inputs and Outputs in Data Envelopment Analysis, European Journal of Operational Research, Vol. 180, No. 2 (2007) pp. 692-699.

Efendigil T., Önüt S., Kongar E., A Holistic Approach for Selecting a Third-Party Reverse Logistics Provider in the Presence of Vagueness, Computers \& Industrial Engineering, Vol. 54, No. 2 (2008) pp. 269-287. 
Farzipoor Saen R., A Mathematical Model for Selecting Third-Party Reverse Logistics Providers, International Journal of Procurement Management, Vol. 2, No. 2 (2009) pp. 180190.

Haas D. A., Murphy F. H., Lancioni R. A., Managing Reverse Logistics Channels with Data Envelopment Analysis, Transportation Journal, Vol. 42, No. 3 (2003) pp. 59-69.

Meade L., Sarkis J., A Conceptual Model for Selecting and Evaluating Third-Party Reverse Logistics Providers, Supply Chain Management: An International Journal, Vol. 7, No. 5 (2002) pp. 283-295.

Min H., Joo S. J., Benchmarking the Operational Efficiency of Third Party Logistics Providers Using Data Envelopment Analysis, Supply Chain Management: An International Journal, Vol. 11, No. 3 (2006) pp. 259-265.

Qureshi M. N., Kumar D., Kumar P., Selection of Potential 3PL Services Providers Using TOPSIS with Interval Data, Proceedings of the 2007 IEEE International Conference on Industrial Engineering and Engineering Management, (2007) pp. 1512-1516.

Talluri S., Baker R. C., A Multi-Phase Mathematical Programming Approach for Effective Supply Chain Design, European Journal of Operational Research, Vol. 141, No. 3 (2002) pp. 544-558.

Zhang Y., Feng Y., A Selection Approach of Reverse Logistics Provider Based on Fuzzy AHP, Proceedings of the Fourth International Conference on Fuzzy Systems and Knowledge Discovery, Vol. 3 (2007) pp. 479-482.

Zhang H., Li X., Liu W., Li B., Zhang Z., An Application of the AHP in 3PL Vendor Selection of a 4PL System, Proceeding of the IEEE International Conference on Systems, Man and Cybernetics, Vol. 2 (2004) pp. 1255-1260. 
Zhang C. Q., Lu Y. C., The Reverse Logistics Evaluation Based on KPCA-LINMAP Model, Proceedings of the Fifth International Conference on Machine Learning and Cybernetics, (2006) pp. 2531-2535. 